$07.2 ; 13.4$

\title{
Генерация шума в одночастотном генераторе на лавинно-пролетном диоде миллиметрового диапазона длин волн под воздействием низкочастотного гармонического колебания
}

\author{
(C) E.A. Мясин \\ Фрязинский филиал Института радиотехники и электроники им. В.А. Котельникова РАН, \\ Фрязино, Московская обл., Россия \\ E-mail: eam168@ms.ire.rssi.ru
}

Поступило в Редакцию 25 июня 2021 г.

В окончательной редакции 30 июля 2021 r.

Принято к публикации 5 августа 2021 г.

\begin{abstract}
Продолжено исследование воздействия низкочастотных гармонических колебаний на цепь питания одночастотного генератора на лавинно-пролетном диоде 7-миллиметрового диапазона длин волн. Впервые показано, что возбуждение шумовых колебаний и максимальное расширение спектра высокочастотного шума в генераторе на лавинно-пролетном диоде при увеличении амплитуды низкочастотных колебаний связаны с кратковременным уменьшением тока диода ниже пускового тока генерации.
\end{abstract}

Ключевые слова: воздействие, низкочастотные гармонические колебания, генератор на лавинно-пролетном диоде, $7 \mathrm{~mm}$ диапазон длин волн, спектр, амплитудный детектор.

DOI: 10.21883/PJTF.2021.22.51724.18937

К настоящему времени исследовано множество разнообразных автоколебательных систем, демонстрирующих хаотическую динамику. Во второй половине прошлого века это были автоколебательные системы на основе электровакуумных приборов, таких, например, как лампа бегущей волны [1-3] и лампа обратной волны [4]. В устройстве, реализующем способ работы, представленный в [1], было впервые показано, что в генераторе из двух ламп бегущей волны 10-сантиметрового диапазона, замкнутых в кольцо, за режим шумовой генерации отвечает одна из них, работающая при глубокой обратной связи в нелинейном режиме, никогда ранее не использовавшемся. Для узкополосных систем, таких как лампа обратной волны, для возбуждения и нелинейного взаимодействия нескольких собственных частот электродинамической системы это условие требует большого превышения рабочего тока над пусковым током.

На основе этого знания с развитием твердотельной электроники оказалось возможным создавать такие системы на самых разнообразных твердотельных приборах с более простыми нелинейными характеристиками и, главное, более простые при использовании (без вакуума и высокого напряжения). Прекрасный обзор истории развития нового направления в радиофизике - хаотической динамики - дан в монографии [5], где целый параграф „Низкочастотное периодическое воздействие на СВЧ-генератор“ посвящен возбуждению сложных и хаотических колебаний в автогенераторе на биполярном $n-p-n$-транзисторе 2Т982А-2 под воздействием регулярного сигнала частотой $9 \mathrm{MHz}$ и амплитудой $1-5 \mathrm{~V}$ от внешнего источника. Результаты проведенного исследования свидетельствуют о широких возможностях управления регулярным низкочастотным (НЧ) сигналом, как характером режима СВЧ-генератора, так и качественными характеристиками его сигнала, с помощью изменения амплитуды и частоты внешнего сигнала.

Однако долгое время верхняя граница частотного диапазона твердотельных приборов (даже транзисторов) ограничивалась сантиметровым диапазоном длин волн. Поэтому в миллиметровом диапазоне в твердотельных генераторах приходилось использовать лавиннопролетные диоды (ЛПД) и диоды Ганна, а для реализации в них режима хаотических колебаний использовать многорезонансные волноводно-коаксиальные камеры, как, например, в генераторе на ЛПД (ГЛПД) [6,7].

В связи с данными [5] по воздействию гармонического колебания на одночастотный транзисторный генератор автор обратил внимание на работу [8]. В [8] было обнаружено неизвестное ранее явление - трансформация спектра одночастотного ГЛПД 3-сантиметрового диапазона длин волн в непрерывный спектр шумового сигнала при воздействии на его цепь питания гармоническим колебанием частотой $150 \mathrm{kHz}$ и $1 \mathrm{MHz}$. Но причина такого поведения ГЛПД в [8] не была выяснена. В недавней работе [9] это явление было детально исследовано при воздействии на ГЛПД 7-миллиметрового диапазона гармонического колебания частотой $3 \mathrm{MHz}$, а именно изучено изменение спектра высокочастотного (ВЧ) сигнала при изменении амплитуды НЧ-колебания воздействия на цепь питания ЛПД. В [9] было показано, что наилучшее условие для реализации режима генерации шума выполняется при выборе рабочей точки вблизи пускового тока одночастотной генерации в ГЛПД, а также предложена гипотеза относительно причины такой трансформации спектра одночастотного сигнала 7-миллиметрового диапазона. Однако для подтвержде- 
ния этой гипотезы необходимо было искать причину указанных изменений спектра во временно́й области.

При поиске в открытом доступе работ, подобных $[8,9]$, в зарубежной литературе XXI века не обнаружено. Все работы в основном направлены на реализацию возможности уменьшения шумовой составляющей в ГЛПД: как давние теоретические (например, [10]), так и давние экспериментальные [11].

В работе [12] впервые было проведено исследование процесса хаотизации колебаний в ГЛПД под воздействием низкочастотных $(3 \mathrm{MHz})$ колебаний не только в спектральной области [9], но и во временно́й области. Осциллограмма сигнала с детектора при генерации СВЧ-шума имела вид неравнобедренного треугольника (вид ,пилы“ ${ }^{“}$. При этом на короткой стороне этой „пилы“ какой-либо сигнал отсутствовал, а на всей длинной стороне наблюдался СВЧ-шум. При высоком разрешении можно было установить, что это очень короткие импульсы со случайной амплитудой и случайными интервалами между ними. Как показано в [12], „по грубой оценке можно считать, что на одно деление в $20 \mathrm{~ns}$ возникает $\sim 10-12$ импульсов разной амплитуды и с разными интервалами между ними, распределенными случайно. Частота этих ВЧ шумовых колебаний $\sim 0.5-0.6 \mathrm{GHz}^{6}$. В работе [12] было сделано предположение, что возбуждение ВЧ шумовых колебаний в одночастотном ГЛПД 7-миллиметрового диапазона обусловлено кратковременным уменьшением тока ЛПД ниже пускового тока возбуждения колебаний в этом генераторе. В [12] также было указано, что подтвердить или опровергнуть это предположение может только одновременное наблюдение изменения характера модуляции СВЧ-колебаний с изменением амплитуды воздействующих НЧ-колебаний. Отметим, что для экспериментов в этом ГЛПД использовалась многорезонансная волноводно-коаксиальная генераторная камера [6,7], специально изготовленная для реализации в ней режима хаотических колебаний.

Задача настоящей работы - исследовать развитие процесса хаотизации колебаний в ГЛПД 7-миллиметрового диапазона при воздействии на цепь питания ЛПД гармонических низкочастотных $(3 \mathrm{MHz})$ колебаний путем наблюдения наряду с изменением спектра СВЧ-сигнала изменения характера модуляции одновременно с изменением амплитуды воздействующих НЧ-колебаний, чтобы подтвердить или опровергнуть выводы, сделанные в [12].

В данной работе эксперименты по воздействию внешнего гармонического низкочастотного (3 MHz) колебания на ГЛПД также 7-миллиметрового диапазона проводились при одновременной фиксации временно́й реализации с детектора и временно́й реализации воздействующего низкочастотного регулярного колебания. Кроме того, решено было исключить возможное влияние автономных режимов генерации СВЧ-шума, которые могли иметь место в волноводно-коаксиальной камере $[6,7]$ при увеличении рабочего тока диода. Поэтому была использована волноводная камера, в которой генерация хаотических колебаний не возбуждалась при увеличении рабочего тока диода от пускового тока (40 mA) до максимального тока (100 mA) при работе в непрерывном режиме. При токе диода $41 \mathrm{~mA}$ и частоте генерации $40.22 \mathrm{GHz}$ при увеличении амплитуды НЧ-колебаний регистрировались как спектр СВЧ-сигнала на анализаторе спектра С4-60, так и временны́е реализации входного НЧ-сигнала воздействия на диоде и сигнала с амплитудного детектора одновременно на двух лучах осциллографа АСК-2104.

По мере увеличения амплитуды НЧ-колебаний происходила трансформация спектра одночастотного СВЧ-сигнала, так же как в работах $[9,12]$ : от одночастотного к многочастотному и затем к непрерывному спектру шумового СВЧ-сигнала. При этом трансформировался и сигнал с детектора. Сначала, при малой амплитуде НЧ-колебания, он повторял синусоидальный характер этого колебания, но по мере увеличения его амплитуды характер модуляции менялся. Она становилась треугольной, причем в виде неравнобедренного треугольника, уже при генерации многочастотного СВЧ-сигнала [13]. Как оказалось в процессе исследования, для этого ГЛПД сигнал с выхода детектора имеет небольшую амплитуду и его можно наблюдать только при включении детекторной секции в основной СВЧ-тракт вместо согласованной нагрузки. При этом перестраиваемый аттенюатор Д3-36А, также расположенный в высокочастотном тракте между выходом генератора и детектором, должен использоваться при нулевом ослаблении. Однако сначала, когда уже наблюдалась генерация шумового СВЧ-сигнала на анализаторе спектра C4-60, сигнал с детектора даже при нулевом ослаблении аттенюатора Д3-36А не мог быть зарегистрирован из-за его малой величины. Это стало возможно на пределе чувствительности осциллографа при генерации шумового сигнала только при амплитуде входного НЧ-колебания на диоде $\sim 1 \mathrm{~V}$. Поэтому никаких особенностей в сигнале с детектора, кроме того, что синусоидальная модуляция на диоде трансформировалась в неравнобедренную треугольную модуляцию, обнаружить не удалось. Дальнейшее увеличение амплитуды входного НЧ-колебания дает возможность увидеть эти особенности, представленные на рисунке, $a, b$.

На рисунке, $a$ при масштабе $20 \mathrm{MHz} / \mathrm{div}$ представлен спектр СВЧ-сигнала, а на рисунке, $b$ - временны́е реализации сигнала воздействия на диоде (луч 1 , амплитуда $\sim 2 \mathrm{~V}$ ) и сигнала с детектора (луч 2 , амплитуда $\sim 20 \mathrm{mV}$ ).

Как видно из рисунка, $a$, ширина спектра СВЧ-сигнала составляет величину порядка $160 \mathrm{MHz}$. Это максимальная ширина спектра шума, которая завершает ее постепенное расширение с увеличением амплитуды НЧ-колебания воздействия. Входной сигнал на диоде (см. рисунок, $b$, луч 1 ) - это почти синусоида. Сигнал с детектора (см. рисунок, $b$, луч 2 ) не только имеет 

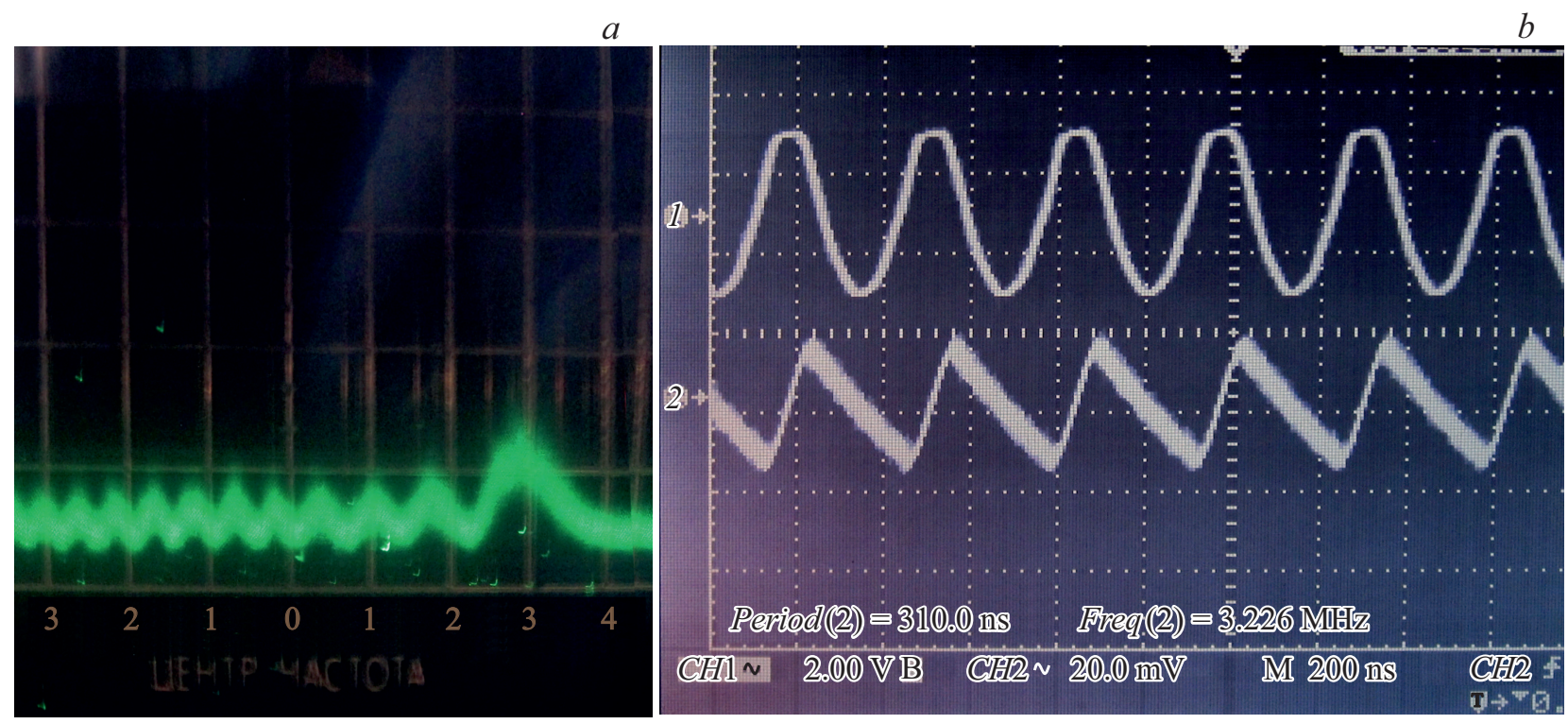

Характеристики режима с непрерывным спектром СВЧ-генерации в ГЛПД при НЧ-воздействии при токе диода $41 \mathrm{~mA} . a-$ спектр СВЧ-сигнала (масштаб $20 \mathrm{MHz} / \mathrm{div}) ; b-$ временны́е реализации: НЧ-колебания сигнала воздействия на диоде (луч 1 , амплитуда $\sim 2 \mathrm{~V}$ ) и сигнала с детектора (луч 2, амплитуда $\sim 20 \mathrm{mV}$ ).

форму неравнобедренного треугольника, но, кроме того, на длинной стороне этого треугольника должны наблюдаться высокочастотные шумовые колебания в виде импульсов со случайной амплитудой и частотой повторения, так же как в работе [12]. Они возникают случайным образом на всей длинной стороне треугольной модуляции, но не могут быть разрешены при этой скорости развертки, которая специально выбрана такой для решения поставленной задачи. Сравнивая реализации на двух каналах осциллографа, можно по временны́м меткам установить причинно-следственную связь двух процессов.

Из рисунка, $b$ (луч 2) видно, что генерация шумового СВЧ-сигнала на длинной стороне треугольной модуляции прекращается, когда положительное значение амплитуды воздействующего низкочастотного гармонического колебания достигает величины, при которой ток диода, уменьшаясь, становится меньше пускового тока, как и утверждалось в работе [12]. Дальнейшее увеличение напряжения воздействия в положительную сторону приводит к прекращению генерации. Она возникает только тогда, когда, уменьшаясь, положительное значение амплитуды воздействующего напряжения вновь достигает величины, соответствующей пусковому току. На основе результатов экспериментов можно сделать следующие выводы.

Гипотеза о том, что процесс генерации шума носит импульсный характер [9], полностью подтвердилась еще в работе [12]. Также подтвердились выводы, сделанные в [12] о причине возникновения неравнобедренной треугольной модуляции на осциллограмме шумового сигнала с детектора. Подтвердился (и это главное) вывод из работы [12] о том, что причиной, приводящей ГЛПД к генерации высокочастотного шума при воздействии низкочастотного гармонического колебания на его цепь питания, является прерывание генерации и возбуждение ее вновь при новых начальных условиях. Это приводит к потере корреляции между СВЧ-колебанием в минимуме „пилы“ и его возникновением в ее максимуме. Именно это обстоятельство должно определять смену многочастотного режима СВЧ-генерации на режим генерации СВЧ-шума.

\section{Финансирование работы}

Исследование проведено при выполнении государственного задания ФИРЭ им. В.А. Котельникова РАН.

\section{Конфликт интересов}

Автор заявляет, что у него нет конфликта интересов.

\section{Список литературы}

[1] Е.А. Мясин, В.Я. Кислов, Э.В. Богданов, Способ генерирования электромагнитных шумовых колебаний, а.с. 1125735 СССР, БЛ № 43 с приоритетом от 22.06.1967 (опубл. 23.11.1984).

[2] В.Я. Кислов, Н.Н. Залогин, Е.А. Мясин, Радиотехника и электроника, 24 (6), 1118 (1979).

[3] В.Я. Кислов, Радиотехника и электроника, 25 (8), 1683 (1980).

[4] Б.П. Безручко, С.П. Кузнецов, Д.И. Трубецков, Письма в ЖЭТФ, 29 (3), 180 (1979).

[5] А.С. Дмитриев, Е.В. Ефремова, Н.А. Максимов, А.И. Панас, Генерация хаоса, под ред. А.С. Дмитриева. Сер. Мир физики и техники (Техносфера, М., 2012), с. 366-368. 
[6] Е.А. Мясин, В.Д. Котов, Радиотехника, № 3, 46 (2005).

[7] Е.А. Мясин, В.Д. Котов, Генератор СВЧ шумовых колебаний, патент № 2614925 РФ, Бюл. № 10 с приоритетом от 17.12. 2015 (опубл. 30.03.2017).

[8] И.А. Кокорин, Электронная техника. Сер. 1, вып. 2, 25 (1984).

[9] Е.А. Мясин, В.Д. Котов, Радиотехника и электроника, 63 (9), 1003 (2018).

[10] A. Sjolund, Int. J. Electron., 34 (4), 551 (1973).

[11] H. Okamoto, M. Ikeda, Injection-locked ultra-high frequency solid-state oscillator, patent US 4099144 A (Publ. date 04. 07.1978).

[12] E.A. Myasin, V.D. Kotov, in Proc. of the 7th All-Russian Microwave Conf. (RMC) (IEEE, 2020), p. 105. DOI: $10.1109 /$ RMC50626.2020.9312231

[13] И.С. Гоноровский, Радиотехнические цепи и сигналь (Сов. радио, 1963), с. 49. 